\title{
IS PETITIO PRINCIPII A PETITIO PRINCIPII?
}

\author{
[ ¿ES LA PETITIO PRINCIPII UNA PETITIO PRINCIPII?]
}

\section{J. Martín Castro-Manzano *}

\begin{abstract}
In this contribution we focus on the petitio principii fallacy and we review it under the tenets of different typical treatments. Then we submit the claim that petitio principii is indeed fallacious, not because of circularity -as the typical treatments suggest-, but because it fails to follow an order relation in Searle and Vanderveken's illocutionary logic. In other words, we claim that, although petitio principii arguments appear to be circular with respect to their propositional content, they are not circular with respect to their illocutionary acts. And hence, even when petitio principii arguments look like propositional loops and instances of reflexivity, they actually constitute a failure in an order relation, a non sequitur as it were.
\end{abstract}

KEYWORDS: Question begging, circularity, illocutionary logic, speech acts, fallacies.
RESUMEN: En esta contribución prestamos atención a la falacia conocida como petitio principii y la estudiamos bajo los principios de varios tratamientos típicos. Posteriormente proponemos la tesis de que la falacia denominada petitio principii es ciertamente falaz, no por ser una instancia de razonamiento circular-como los tratatimentos típicos sugieren-, sino porque no sigue una relación de orden en la lógica ilocucionaria de Searle y Vanderveken. En otras palabras, sugerimos la tesis de que una petitio principii, si bien tiene la apariencia de ser circular con respecto a su contenido proposicional, no es circular con respecto a sus actos ilocucionarios. Y por tanto, aun cuando una petitio principii aparenta ser un bucle proposicional y una instancia de reflexividad es, como un non sequitur, un error en una relación de orden.

Palavras Clave: Petición de principio; circularidad; lógica ilocucionaria; actos de habla; falacias

\section{INTRODUCTION}

Fallacies have been traditionally defined as patterns of poor (i.e. invalid) reasoning that appear to be good (i.e. valid); however, this traditional approach has proved to be quite problematic and unsatisfactory (cf. Hansen, 2000; Hamblin, 1970, p.12), and consequently, several projects have emerged in order to overcome its issues.

* Faculty of Philosophy, People's Autonomous University of Puebla State, Mexico (UPAEP). m@ilto:jmcmanzano@hotmail.com 
We believe, nevertheless, that by assuming the traditional stance we can still obtain some interesting results. To show how this is so, we focus on petitio principii-a fallacy also known as question begging - and we review it under the tenets of different treatments. Then we submit the claim that petitio principii is indeed fallacious, but not because of circularity - as the typical treatments suggest-, but because it does not verify an order relation (using Searle and Vanderveken's illocutionary logic), which turns out to be a rather traditional solution.

\section{A BRIEF SURVEY ON PETITIO PRINCIPII}

Petitio principii (PP) is simple yet puzzling. It is a rather simple fallacy to explain: consider, for example, the typical accounts we find on logic manuals (Copi \& Cohen, 1990) or the web (Begging the question, 2018; Begging the Question, n.d.; Petitio Principii, 2018). Typically, these accounts define a PP as some sort of circular reasoning and, in some cases, they even provide a propositional model of the form " $p \vdash p$ " or " $p_{1}, \ldots, p_{k}, \ldots p_{n} \vdash p_{k}$ " in order to explain it; and yet, despite this simplicity, PP arguments are puzzling because their seemingly valid logical structure requires explanations ever more complex than the structure itself.

Aristotle, for example, suggested that a PP was a fallacy because it failed to account for causal explanations since it depended upon assuming what was to be explained (De Sophisticis Elenchis 168b23-27). This Aristotelian description shows the recognition of circularity as in the model " $p \vdash p$," for it is a requirement of a legitimate reasoning that the conclusion (i.e., what has to be explained) has to be different from the premises (Topics 100a25-26, De Sophisticis Elenchis 165a1-2, Prior Analytics 24b1920). However, as we will see in the next section, the very recognition of circularity introduces a problem with the reflexivity of inference. Thus, for instance, Peter of Spain had to introduce an interesting but artificial distinction between an inferring syllogism and a probative syllogism in order to avoid such problem: according to this distinction we should say that PP's circularity is no impediment to an inferring syllogism, but only to a probative one (Summulae Logicales 7.54).

In a more recent account, Copi \& Cohen $(1990$, p.91) describe fallacies as errors of reasoning. They suggest that PP is a fallacy that consists in assuming the truth of what one seeks to prove in the effort to prove it. Likewise, for Cohen \& Nagel (1934), $\mathrm{PP}$ is claiming to have proved a proposition when it has been smuggled, in some more or less disguised form, into the premises. But oddly enough, these two accounts consider that $\mathrm{PP}$ is, at the same time, an error of reasoning and a valid inference of the form " $p \vdash p$ " (Cohen \& Nagel, 1934, p.379; Copi \& Cohen, 1990, p.103).

For Walton, however, it is clear that PP is not a fallacy that can, at least straightforwardly, be modeled propositionally because the pattern " $p \vdash p$ " is deductively valid (Walton, 1994). Walton, therefore, is aware of the tension implied in asserting that a fallacy is both an error of reasoning and a valid inference. Thus, Walton takes a pragmatic turn in order to solve the puzzling nature of PP and, by doing an analysis of 
several cases, he reaches the conclusion that not all circular arguments commit a fallacy and that, when the fallacy occurs, it is because of a failure in the probative function of the argument that prevents it from fulfilling the goals of a dialogue in which an arguer is supposed to be engaged. In this approach, Walton implicitly provides a rule of thumb to determine whether there is a PP in a given dialogue (1994, p.129). This treatment, however, assumes that the problem with PP is circularity. His rule implies that in some cases circularity occurs and in some other cases it does not, which is the same as saying that in some cases a PP occurs and in some cases it does not. And when it does not occur it is because a context blocks the circularity. Therefore, under this approach, PP would have the form " $p \vdash_{c x} p$ " where $c t x$ stands for a context that can be evaluated. And hence, while Walton's approach is certainly more parsimonious than the previous ones, its pragmatic nature still accepts the notion of circularity with the useful addition of context evaluation.

Suber's take on PP is similar to Walton's but requires another set of distinctions (Suber, 1994). According to this new set of distinctions, a classical model of reasoning is vertical and a non-classical model is horizontal. In general, reasoning is foundational, and horizontal reasoning is non-foundational or coherentist. In vertical reasoning, arguers establish conclusions; in horizontal reasoning, arguers establish a linkage among propositions. Following Suber, then, the vertical and horizontal models of reasoning understand PP differently. The inference pattern " $p \vdash p$ " does not establish the conclusion and hence it fails by the tenets of the vertical model, but it does link the premise with the conclusion by means of an acceptable rule of inference, i.e., it succeeds by the tenets of the horizontal model. Suber concludes, hence, that PP succeeds at the logical task of argument for the horizontal argumentation; but fails at the social task: the argument establishes the conclusion but fails to link the conclusion to a premise that the unconvinced would find more acceptable than the conclusion. Now, however interesting these distinctions may be, this account assumes that PP is, again, not a sequence but a propositional loop.

The pragma-dialectical approach, as provided by Eemeren \& Grootendorst (1995), has its take on PP as well. In this approach, one starts by noting that argumentation is part of a reasonable argumentative discourse aimed at resolving a difference of opinion. So, given a critical discussion, the protagonist and the antagonist of a standpoint at issue must in all stages of the discussion observe the rules that are instrumental to resolving the dispute. Under this treatment, hence, when one advances information that amounts to the same thing as the standpoint, one breaks a particular rule, namely, that a party may not falsely present a premise as an accepted starting point nor deny a premise representing an accepted starting point. This treatment, once again, assumes PP is defined in terms of circularity.

More recently, Wright (2002) proposed a solution in which the problem with PP was not its validity but the failure of the transmission of warrant from the premises to the conclusion. Ritola $(2003,2006)$ and Truncellito (2004), also aware of the puzzling nature of PP, made further distinctions in order to avoid the tensions between fallaciousness and circularity: the former, in terms of epistemic accounts; the latter, in terms of logical and rhetorical fallacies. And Sgaravatti (2013) has developed another succcesful account of PP in terms of evidential states and doxastic justifications. 


\section{IS PETITIO PRINCIPII A PETITIO PRINCIPII? A SOLUTION WITH ILLOCUTIONARY LOGIC}

The existence of the previous proposals suggests that the importance of PP and its issues are far from being overstated, but the very presence of so many distinctions, however clever or successful, may lead to a natural skepticism about the criterion to decide whether PP is a fallacy at all (Ikuenobe, 2002). Nevertheless, in spite of this potential skepticism, there is little doubt, as the previous survey indicates, that PP has been systematically dubbed "PP" because of a notion of circularity that, ultimately, takes the propositional form " $p \vdash p$ ".

This, nonetheless, does not seem to be quite right because from such assumption we get the undesired side effect of taking the axiom of identity (i.e. " $p \vdash p$ ") and deeming it a fallacy. But this effect strikes us as counter-intuitive, since it would imply the rejection of the very notion of validity. Consider that an inference is valid if and only if it is impossible for its premises to be true and its conclusion to be false. Hence the axiom " $p \vdash p$ " is valid (since it is impossible for its premises to be true and its conclusion to be false). But also, consider that fallacies are invalid inferences, hence " $p \vdash p$ " is invalid (since it is claimed " $p \vdash p$ " is a fallacy). But then, arguing that " $p \vdash p$ " is a fallacy amounts to arguing that " $p \vdash p$ " is invalid, which amounts to arguing that a valid inference is invalid.

But if the assumption that PP is circular reasoning leads us to the rejection of the notion validity, then such assumption should be false. In other words, if all these distinctions and proposals are needed in order to avoid tensions between fallaciousness and circularity, and these tensions come from the assumption that PP is circular reasoning of the form " $p \vdash p$ ", then maybe this form, in spite of being popular, is not a good model of PP.

Consequently, we suggest a solution to this issue with illocutionary logic. Since we think a model of PP within a first order system enriched with alethic acts (Siegwart, 2007) or speech acts constants (Searle \& Vanderveken, 1985) can do the job, here we use the logical system S\&V (see the Appendix). It just might avoid the tensions between fallaciousness and circularity without leading to skepticism about the fallacious nature of PP while being compatible with other solutions.

So, in this paper we advance the next two models or representations of PP:

$$
\begin{aligned}
& \| \text { Assert }\left\|_{(a, j)}\left(p_{i}\right) \rightarrow\right\| \text { Assure } \|_{(a, j)}\left(p_{i}\right) \\
& \| \text { Assert }\left\|(\mathrm{a}, \mathrm{j})\left(p_{i}\right) \rightarrow\right\| \text { Argue } \|_{(a, j)}\left(p_{i}\right)
\end{aligned}
$$

where $a$ stands for an agent that executes certain speech acts in a context of utterance $j$ with propositional content $p_{i}$, namely, $\|$ Assure $\|$, and $\|$ Assert|| in model [1], and $\|$ Argue $\|$ in model [2]. We shall argue that models [1] and [2] are invalid in $\mathrm{S} \& \mathrm{~V}$, that is to say, that $\|$ Assert|| does not entail \|Assure\| nor \|Argue $\|$. To show how this is so, consider the following remarks. 
Remark 1. ||Assert $\|$ is a primitive illocutionary act.

According to $\mathrm{S} \& \mathrm{~V}, \|$ Assert $\|$ is a primitive illocutionary act, which means that the illocutionary force of assertion is assertion itself, i.e., $\|$ Assert $\|=\vdash$ (Appendix, Definition 3), and consequently, $\|$ Assert $\|$ is basic and other assertive illocutionary acts depend upon it.

Remark 2. \|Assure $\|$ is a mode of $\|$ Assert $\|$.

When a speaker assures that $p$ is the case, she tries to make a hearer feel sure because the hearer may have doubts about $p$. To assure, hence, is to assert with the particular intention of convincing the hearer of the truth of the propositional content in the world of utterance. This increases the degree of strength of the illocutionary point and determines the preparatory conditions that the hearer has doubts about $p$ (Searle \& Vanderveken, 1985, p.184).

Remark 3. $\|$ Argue $\|$ is a mode of $\|$ Assert $\|$.

Now, when a speaker argues that $p$, she asserts $p$ with reasons of support for $p$ plus the intention of convincing a hearer of the truth of $p$ (Searle \& Vanderveken, 1985, p.184). Hence, $\|$ Argue $\|$ is a mode of $\|$ Assure $\|$ and, by transitivity, it is also a mode of $\|$ Assert\|.

With this framework in mind, consider the next pair of propositions.

Proposition 1. Model [1] is invalid in S\&V.

Let us fix the arbitrary propositional content $p_{i}$, agent $a$, and context of utterance $j$. Now consider that, by definition, $\|$ Assure $\|=[\mu]||$ Assert $\|$ (by Remark 1), where $\mu\left(j, p_{i}\right)=1$ iff mode $(\|$ Assert $\|)\left(j, p_{i}\right)$ and $\mu=1$; hence, by Remark 5, Law 2 (vide Appendix), it follows that $[\mu] \|$ Assert $\|\rightarrow\|$ Assure $\|$, that is to say, that $\|$ Assert $\|$ and $\|$ Assure $\|$ differ in that the mode of achievement of $\|$ Assert $\|$ is a restriction of the mode of achievement of $\|$ Assure $\|$ so that the act $\|$ Assure $\|$ cannot be achieved without achieving \|Assert\|, but not conversely, which implies that \|Assert|| does not entail \| Assure $\|$. In other words, even though $\|$ Assert $\|_{(a, j)}\left(p_{i}\right)$ holds, $\|$ Assure $\|_{(a, j)}\left(p_{i}\right)$ does not obtain.

The previous argument can be simplified if we attend to the structure of paths in the assertives tableau (vide Appendix, Figure 1): since there is no path starting at node $\|$ Assure $\|$ and ending at node $\|$ Assert $\|$, model [1] is invalid in S\&V. Consequently, we can suggest a simpler justification of the remaining proposition: since there is no path in the tableau that starts in $\|$ Argue $\|$ and ends in $\|$ Assert\|, model [2] fails; that is to say, ||Argue $\|$ cannot be achieved without achieving ||Assert $\|$, but not conversely: 
Proposition 2. Model [2] is invalid in S\&V.

Informally, these results mean that we cannot accept an inference from asserting to assuring (Proposition 1) or from asserting to arguing (Proposition 2) as a sound one, even if the propositional content is the same. But then PP would not be a fallacy due to circularity; it would be a fallacy because of a failure in an order relation between speech acts - a fact that can verified in the tableau. In other words, we may have the impression that a PP argument is circular because it appears to be circular with respect to its propositional content, but it is clear it is not circular with respect to its illocutionary acts. And hence, even when a PP argument looks like a propositional loop and an instance of identity, it constitutes a failure in an order relation, a non sequitur as it were, and this solution seems to be a rather traditional one.

\section{Conclusions}

To wrap this up, with this illocutionary solution not only we avoid the rejection of identity (a side effect of usual treatments), we also suggest a formal setting that, far from pragmatic trends but compatible with, is closer to a tradition that defines a fallacy as a pattern of poor reasoning (in this case, a non sequitur instance) that appears to be good (in this case, an instance of identity). Perhaps it is fair to say, then, that petitio principii is not really a petitio principii, so to speak.

Finally, we would like to mention that, although in this short contribution we have focused on a single but problematic mainstream fallacy, we believe this illocutionary approach has explanatory advantages in so far as it can be used to explain other fallacies. For example, consider the fallacy known as ad populum, in which an agent asserts a proposition solely on the grounds that most agents assert it, so that the root of the justification of the proposition ultimately depends on the size (\#) of the sample of agents that assert the proposition. Thus, we could advance a couple of models or representations:

$$
\begin{aligned}
& \| \text { Assert }\left\|_{(a, \# s>\# h)}\left(p_{i}\right) \rightarrow\right\| \text { Assure } \|_{(a, j)}\left(p_{i}\right)[3] \\
& \| \text { Assert }\left\|_{(a, \# s>\# h)}\left(p_{i}\right) \rightarrow\right\| \text { Argue } \|_{(a, j)}\left(p_{i}\right)
\end{aligned}
$$

where the agent $a$ is in a context of illocution in which the sample of speakers is greater than the sample of hearers (\#s>\#h). With these models in mind, consider what would happen in case \#s=\#h. Under this assumption, we can see that model [3] (and [4]) collapses with model [1] (and [2]), which we know is invalid in S\&V. Consequently, we could state, by following this illocutionary framework, that:

Corollary 1. Ad populum fallacies are generalizations of petitio principii fallacies. 
This sounds about right, for we usually consider ad populum arguments as fallacies on the ground that the mere assertion of a proposition is not a proof nor a justification of the proposition, regardless of the number of agents that assert said proposition.

\section{REFERENCES}

AUSTIN, John Langshaw. How to do things with words. Cambridge: Harvard University Press, 1962.

BEGGING THE QUESTION. (2018, June 25). Retrieved June 30, 2018, from https://en.wikipedia.org/wiki/Begging_the_question\#Definition.

BEGGING THE QUESTION. (n.d.) Retrieved June 30, 2018, from http://www.fallacyfiles.org/begquest.html.

COHEN, Morris Raphael \& NAGEL, Ernest. An introduction to logic and the scientific method. New York: Harcourt, Brace, 1934.

COPI, Irving M. \& COHEN, Carl. Introduction to logic. New York: Macmillan, 1990.

HANSEN, Hans Vilhelm. "The Straw Thing of Fallacy Theory: The Standard Definition of 'Fallacy'”. Argumentation, 16(2), 133-55, 2002. Doi:10.1023/A:1015509401631.

IKUENOBE, Polycarp. "In Search of Criteria for 'Fallacies' and 'Begging the Question"”. Argumentation, 16(4), 421-441, 2002. Doi:10.1023/A:1021158632437.

PETITIO PRINCIPII. (n.d.) Retrieved June 30, 2018, from http://philosophy.lander.edu/logic/circular.html.

RITOLA, Juho. "Begging the question: a case study". Argumentation, 17(1), 1-19, 2003. Doi:10.1023/a:1022908405402.

RITOLA, Juho. "Justified and Justifiable Beliefs: The Case of Question-Begging”. Philosophical Studies, 128(3), 565-83, 2006. Doi:10.1007/s11098-004-7822-1.

SIEGWART, Geo. "Alethic acts and alethiological reflection. An outline of a constructive philosophy of truth". In Greimann D. and Siegwart G. (Eds.). Truth and speech acts: studies in the philosophy of language (pp. 41-58). New York: Routledge, 2007.

SEARLE, John R. Speech acts: an essay in the philosophy of language. London: Cambridge University Press, 1969.

SEARLE, John R. \& VANDERVEKEN, Daniel. Foundations of illocutionary logic. Cambridge: Cambridge University Press, 1985.

SGARAVATTI, Daniele. "Petitio Principii: A Bad Form of Reasoning”. Mind, 487, 749-79, 2013. Doi:10.1093/mind/fzt086.

SUBER, Peter. "Question-begging under a non-foundational model of argument". Argumentation, 8(3), 241-50, 1994. Doi:10.1007/bf00711191.

TRUNCELLITO, David A. "Running in Circles about Begging the Question". Argumentation, 18(3), 325-29, 2004. Doi:10.1023/b:argu.0000046731.07528.75.

VAN EEMEREN, Frans H. \& GROOTENDORST Rob. "The pragma-dialectical approach to fallacies". In Hansen, H.V. and Pinto R. (Eds.). Fallacies: classical and contemporary readings (pp. 130-144). Pennsylvania: Pennsylvania State University Press, 1995.

WALTON, Douglas. "Begging the question as a pragmatic fallacy." Synthese, 100(1), 95-131, 2004. Doi:10.1007/bf01063922.

WRIGHT, Crispin. "(Anti-)Sceptics Simple and Subtle: G.E. Moore and John McDowell”. Philosophy and Phenomenological Research, 65 (2), 330-48, 2002. Doi:10.1111/j.19331592.2002.tb00205.x. 


\section{APPENDIX}

After the foundational works of Austin (1962) and Searle (1969), it has been argued that the minimal units of human communication are speech acts of a type called illocutionary acts (Searle \& Vanderveken, 1985, p.1). These occur when speakers utter sentences in certain contexts and with certain intentions. Thus, for example, assertions, promises, commands, declarations, and apologies are illocutionary acts. Informally, an illocutionary act is defined by an illocutionary force and a propositional content. The utterances "Close the door" and "Could you please close the door?" have the same propositional content but different force; inversely, the utterances "Two plus two equals four" and "2 is a prime number" have the same force but different propositional content. Illocutionary logic is the logic that studies these components and defines inference between illocutionary acts. $\mathrm{S} \& \mathrm{~V}$, in particular, is a logic of illocutionary entailment (Searle \& Vanderveken, 1985, p.6). In this appendix we show the semantics of illocutionary verbs that define relations of illocutionary entailment.

Illocutions are given in a context of utterance where speakers, hearers, times, places, and possibilities are involved, and each type of illocution has a purpose or point. The point of assertions (assertive illocutionary point) is the description of a state of affairs. The point of promises (commissive illocutionary point) is to commit a speaker into carrying out a course of action. The point of commands (directive illocutionary point) is to commit the hearer into carrying out a course of action. The point of declarations (declarative illocutionary point) is to perform an act by declaring the act. The point of expressions (expressive illocutionary point) is to express feelings and attitudes of the speaker.

Definition 1 (Context of utterance) Let $S$ be a set of speakers, $H$ be a set of hearers, $T$ a set of times, $P$ a set of places, and $W$ a set of possible worlds. A context of utterance $I \subset S \times H \times T \times P \times W$ is defined by $i=<s_{i}, h_{i}, t_{i}, p_{i}, w_{i}>$.

Definition 2 (Illocutionary point) An illocutionary point $\mathrm{F} \in \Phi$ is defined by a relation $\Pi$ on $I \times$ Prop s.t. $i \prod_{\mathrm{F}} p$ iff $s_{i}$ in $i$ succeeds in achieving the illocutionary point $\mathrm{F}$ on $p$.

The conditions of achievement are defined for assertives $\left(\Pi_{1}\right)$, commissives $\left(\Pi_{2}\right)$, directives $\left(\Pi_{3}\right)$, declaratives $\left(\Pi_{4}\right)$, and expressives $\left(\Pi_{5}\right)$. The assertive illocutionary point is defined as follows.

Definition 3 (Assertive illocutionary point) A speaker $s_{i}$ succeeds in achieving an assertive illocutionary point on $p$ in context $i, i \Pi_{1} p$, iff in $i, s_{i}$ represents the state of affairs that $p$ is the case in $w_{i}$. 
Similarly, $i \Pi_{2}$ p iff $s_{i}$ commits to carrying out a course of action on $p . i \Pi_{3} p$ iff $s_{i}$ attempts to get $h_{i}$ to carry out $p . i \Pi_{4} p$ iff $s_{i}$ brings about $p$ by her utterance in $i . i \Pi_{5} p$ iff $s_{i}$ expresses her feelings about $p$.

Some illocutionary acts require special conditions under which their illocutionary point have to be achieved in the performance of the speech act. For example, a speaker who issues a command from a position of authority does more than someone who just makes a request. Thus, there are modes of achievement.

Definition 4 (Mode of achievement) The mode of achievement is a function $\mu: I \times$ Prop $\rightarrow\{1,0\}$ s.t. $\mu(\Pi)=1$ iff $s_{i}$ is committed to $\Pi$ on $p$ in $i$.

Equivalently, $\operatorname{mode}(\mathrm{F})(i, p)=1$ iff $s_{i}$ in $i$ achieves $\Pi_{\mathrm{F}}$ on $p$ in the mode required by $\mathrm{F}$. So, for example, mode $(\|\operatorname{Order}\|)(i, p)=1$ iff $s_{i}$ in $i$ achieves the directive illocutionary point on $p$ by invoking authority on $h_{i}$.

Now, illocutionary acts may achieve the same illocutionary point but with different degrees of strength. So, for example, if a speaker conjectures that "Puebla is in Mexico" her point is weaker than her assurance of the same propositional content.

Definition 5 (Degree of strength) The degree of strength of the illocutionary point is a function degree: $\Phi \rightarrow \mathrm{Z}$ s.t. degree $(\mathrm{F})$ is the integer that represents the strength with which $\Pi_{\mathrm{F}}$ is achieved. $i \prod_{\mathrm{F}}^{k} p$ means $s_{i}$ in $i$ achieves $\Pi_{\mathrm{F}}$ on $p$ with degree of strength $k$.

In some other cases, an illocutionary act may impose some propositional content conditions. For instance, when a speaker issues an order, the content of the order must not imply an impossible instruction: a speaker cannot order a hearer to speak fluently if the hearer is mute, for example.

Definition 6 (Propositional content conditions) The propositional content conditions are defined by a function $\Theta: I \rightarrow \wp($ Prop $)$ s.t. $\Theta$ maps each context of utterance to a set of propositions having a particular feature.

So, for example, $\Theta_{\text {future }}=\operatorname{Prop}_{\| \text {rredict|l }}$, that is to say, that predictions require assertions about future states of affairs; and $\operatorname{Prop}_{\| \text {Assert| }}(i)=\operatorname{Prop}$, that is to say, that assertions have empty propositional conditions.

Further, consider the case of an apology. If a speaker apologizes to a hearer, she presupposes that the thing she apologizes for is morally reprehensible, for otherwise there would be no need of an apology. So there are preparatory conditions for illocutionary acts.

Definition 7 (Preparatory conditions) The preparatory conditions of an illocutionary point are defined by a function $\Sigma: I \times$ Prop $\rightarrow \wp($ Prop $)$ s.t. $\Sigma$ maps an illocutionary point to a set of propositions having pre-conditions. 
For example, $\Sigma_{\| \text {Assert } \|}(i, p)=\left[\left\{\rho s_{i} t_{i} p\right\}\right]$, i.e., the preparatory conditions of an assertion require $s_{i}$ to have reasons for the truth of $p$ at $t_{i}$, which is denoted by $\rho$.

Also, when a speaker makes an illocutionary act she expresses a certain psychological state. When she gives an assertion, her intentional attitude is belief; when she makes a promise, her psychological state is intention; when issues a command, she expresses a desire: these are examples of sincerity conditions.

Definition 8 (Sincerity conditions) Sincerity conditions of an illocutionary point are defined by a function $\Psi: I \times$ Prop $\rightarrow \wp(M \times$ Prop $)$.

For instance, $\Psi_{\|\operatorname{Assert}\|}(i, p)=[\{\operatorname{BEL}(p)\}]$ and $\Psi_{\| \operatorname{Beg}||}(i, p)=[\{\operatorname{DES}(p)\}]$, that is to say, that the sincerity conditions of assertions are beliefs and the sincerity conditions of beggings are desires. But notice that these sincerity conditions also come in degrees. For example, if a speaker implores or begs for something, she expresses a stronger desire than if she merely requests it. So, there are degrees of sincerity conditions.

Definition 9 (Degree of strength of sincerity conditions) The degree of strength of sincerity conditions are defined by a function $\eta: \Psi \rightarrow Z$.

With these basic components, an illocutionary act or speech act is defined as follows:

Definition 10 (Illocutionary act) An illocutionary act is a structure $\mathrm{F}(p)$ s.t. $\mathrm{F}(p)=<\Pi_{\mathrm{F}}, \mu$, degree, $\Theta, \Sigma, \Psi, \eta>$, where $\Pi_{\mathrm{F}}$ is the illocutionary point, $\mu$ is the mode of achievement of the illocutionary point, degree is the degree of strength with which the illocutionary point is achieved, $\Theta$ represents propositional content conditions, $\Sigma$ stands for preparatory conditions, $\Psi$ stands for sincerity conditions, and $\eta$ is the degree of strength of sincerity conditions. Thus, an illocutionary act $\mathrm{F}(p)$ is a structure defined by $\mathrm{F} \in \Phi \subset \wp\left(I \times P_{\text {Prop })} \times 2^{I \times P r o p} \times \mathrm{Z} \times \quad(\wp(\text { Prop }))^{I} \times(\wp(\text { Prop }))^{I \times P r o p} \times \wp\left(M \times\right.\right.$ Prop $^{I \times P r o p} \times \mathrm{Z} \quad$ and $p \in$ Prop.

Consequently, illocutionary logic is the logic that defines entailment between illocutionary acts:

Definition 11 (Illocutionary entailment) Let $F_{1}$ and $F_{2}$ be illocutionary acts. $F_{1}$ entails $F_{2}$ $\left(\mathrm{F}_{1} \rightarrow \mathrm{F}_{2}\right)$ iff for all $p \in$ Prop, all conditions of success of $\mathrm{F}_{2}(p)$ are conditions of success of $\mathrm{F}_{1}(p)$, i.e., $\left\{i / \mathrm{F}_{2}(p)\right.$ is performed in $\left.i\right\} \subseteq\left\{i / \mathrm{F}_{1}(p)\right.$ is performed in $\left.i\right\}$.

Remark 4 Illocutionary entailment is a partial order on $\Phi$.

Remark 5 Illocutionary entailment may occur by way of:

Law 1 . The degree of strength: $[+1] \mathrm{F} \rightarrow \mathrm{F}, \mathrm{F} \rightarrow[-1] \mathrm{F}$. 
Law 2. The mode of achievement: $[\mu] \mathrm{F} \rightarrow \mathrm{F}$.

Law 3. The propositional content conditions: $[\Theta] \mathrm{F} \rightarrow \mathrm{F}$.

Law 4 . The preparatory conditions: $[\Sigma] \mathrm{F} \rightarrow \mathrm{F}$.

Law 5 . The sincerity conditions: $[\Psi] \mathrm{F} \rightarrow \mathrm{F}$.

Proposition 3 (A completeness theorem) An illocutionary act $F_{1}$ entails an illocutionary act $F_{2}$ with the same point iff it can be obtained from $F_{2}$ by applying the operations in Remark 4.

This high-level account of illocutionary entailment can be grounded with illocutionary verbs in a natural language: illocutionary verbs name illocutionary acts. Table 1 shows a few examples.

\begin{tabular}{ccccc}
\hline Assertives & Commissives & Directives & Declaratives & Expressives \\
\hline Confess & Swear & Supplicate & Excommunicate & Condole \\
Argue & Consent & Command & Curse & Deplore \\
Report & Pledge & Demand & Bless & Congratulate \\
Assert & Promise & Request & Endorse & Thank \\
Insist & Threaten & Beg & Nominate & Praise
\end{tabular}

Table 1. Examples of illocutionary verbs

When the illocutionary act named by an illocutionary verb $F_{2}$ is obtained from the illocutionary act named by an illocutionary verb $F_{1}$ by successive applications of operations on illocutionary forces of restricting the mode of achievement, increasing the degrees of strength and adding propositional content, preparatory, and sincerity conditions, the illocutionary force $F_{2}$ entails the illocutionary force $F_{1}$, due to Proposition 3. In these cases the expression $F_{1} \rightarrow F_{2}$ stands for " $F_{1}$ is derived from $F_{2}$ by applying one or more operations". In $\mathrm{S} \& \mathrm{~V}$ it is possible to define tableau (as in Figures $1 \mathrm{a}, 1 \mathrm{~b}, 1 \mathrm{c})$ for illocutionary entailment with the next items:

- A set $F$ of illocutionary verbs.

- A function $\lambda: F \rightarrow \mathrm{Z}^{+}$called "level of $f$."

- A relation $\rightarrow$ on $F$ s.t. for any pair of verbs $f f^{\prime} \in F, f^{\prime} \rightarrow f$ iff $f^{\prime} \rightarrow f$ and for no $f$ " $\in F$, both $f^{\prime} \rightarrow f$ " and $f^{\prime \prime} \rightarrow f$ '. $f$ ' $\rightarrow f$ is read as " $f$ ' is an immediate linguistic successor of $f$ in $F$." This relation follows two conditions: $i$ ) there is a unique illocutionary verb of level 1 (which is the root of the tableau); and ii) for any illocutionary verbs if $f^{\prime} \rightarrow f$, 
then $\lambda\left(f^{\prime}\right)=\lambda(f)+1$. An illocutionary verb belonging to $F$ is an end point if it has no successor. A path is any finite sequence of illocutionary verbs: if there is a path in a tableau where the first and last terms are $f_{1}$ and $f_{2}$, then $F_{2} \rightarrow F_{1}$.

In $\mathrm{S} \& \mathrm{~V}$ we have illocutionary entailment within assertives, commissives, and directives. For the purposes of this paper we focus only in the assertives and notice that entailment between illocutionary verbs must be read from top to bottom. For example, in Figure 1 we see that $\|$ Confess $\|$ illocutionary entails $\|$ Admit $\|$ (by propositional content and preparatory conditions) and that ||Admit|| entails ||Assert|| (by preparatory conditions), but not inversely, because there is a path starting in $\|$ Confess $\|$ and ending in \|Assert\|.

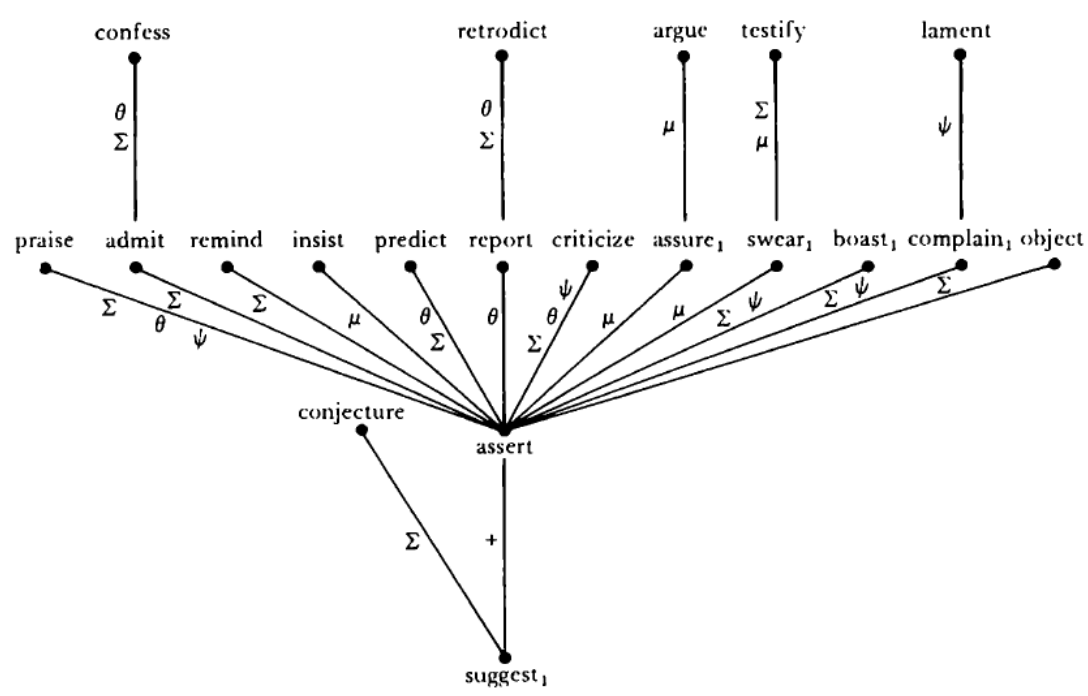

Figure 1. Assertives tableau taken from (Searle \& Vanderveken, 1985, p.218) 